\title{
EVOLUCÃO E MAGNITUDE DAS CONCENTRACCÕES DE CÁTIONS, ÂNIONS E CARBONO NO DEJETO LÍQUIDO DE SUÍNOS EM FASE DE TERMINAÇÃO
}

\author{
Rafael Gotardo* \\ Adilson Pinheiro** \\ Leandro Mazzuco Aguida*** \\ Vander Kaufmann ${ }^{* * * *}$
}

RESUMO: O dejeto líquido suíno constitui importante fonte de nutrientes ao solo, melhorando suas condições físicas, químicas e biológicas. Suas características variam ao longo do tempo, com o manejo dos animais e pelo sistema de tratamento adotado pela granja. As espécies químicas aniônicas, catiônicas e carbono são as que mais apresentam mudanças em suas concentrações ao longo do tempo. Diante disso o estudo teve por objetivo avaliar a magnitude das concentrações e a evolução de cátions, ânions e carbono nos dejetos líquidos suínos em fase de terminação com sistema de tratamento anaeróbico. O estudo consistiu na coleta do dejeto líquido de suínos de três granjas com sistema integrado de criação, na fase de terminação dos animais, sendo realizadas nas calhas de entrada do dejeto e na saída do sistema de tratamento, ao longo de 120 dias do período de alojamento dos animais. As campanhas foram realizadas mensalmente, a partir do alojamento dos animais. As concentrações de espécies catiônicas e aniônicas foram analisadas em Cromatógrafo de Troca Iônica e o carbono total em Analisador de Carbono Total. Os resultados apresentados mostraram que $\mathrm{Cl} ; \mathrm{NH}_{4}^{+} \mathrm{e} \mathrm{CI}$ não apresentaram diferenças significativas entre as granjas. No entanto, as demais espécies químicas apresentaram diferenças significativas. A esterqueira mostrou-se com alta eficiência na remoção dos íons $\mathrm{NO}_{2}, \mathrm{NO}_{3}^{-}$e baixa remoção para os íons $\mathrm{NH}_{4}^{+}$. Durante o período de terminação dos animais as concentrações dos íons $\mathrm{Cl}^{-}, \mathrm{NH}_{4}^{+}$e $\mathrm{Ca}^{+2}$ aumentaram, enquanto as demais espécies químicas reduziram ou mantiveram suas concentrações.

PALAVRAS-CHAVE: Resíduo agropecuário; Suinocultura; Tratamento.

Engenheiro Agrônomo, Doutorando em Engenharia Ambiental pelo Programa de Pós-Graduação em Engenharia Ambiental da Fundação Universidade Regional de Blumenau (FURB), Brasil. E-mail: Rafael Gotardo $<$ dr.rafaelgotardo@gmail.com>

** Engenheiro Civil, Doutor em Física e Química Ambiental; Docente do Departamento de Engenharia Civil da Fundação Universidade Regional de Blumenau (FURB), Brasil.

*** Mestre em Engenharia Ambiental pelo Programa de Pós-Graduação em Engenharia Ambiental da Fundação Universidade Regional de Blumenau (FURB), Brasil.

**** Doutor em Recursos Hídricos e Saneamento Ambiental; Pós doutorando e Docente colaborador do Programa de Pós-Graduação em Engenharia Ambiental da Fundação Universidade Regional de Blumenau (FURB), Brasil. 


\section{EVOLUTION AND GREATNESS OF CATION, ANION AND CARBON CONCENTRATIONS IN FINISHING SWINE LIQUID WASTES}

ABSTRACT: Swine liquid wastes are an important nutrient source for physical, chemical and biological soil improvement. Characteristics change through time according to the management of animals and to farm treatment system. Anion, cation and carbon species have the greatest concentration changes in time. Current study evaluates concentration size and anion, cation and carbon evolution in finishing swine liquid wastes through anaerobic treatment system. Swine liquid wastes were collected from three farms characterized by integrated breeding system during the animals' finishing phase. Collection occurred in the waste gut entrance and exit of the treatment system during 120 days in which the animals were installed. Retrieval occurred monthly within the bays. Anion, cation and carbon concentrations were analyzed by Ion Exchange Chromatograph, whilst total carbon was determined by Total Carbon Analyzer. Results revealed that $\mathrm{Cl}, \mathrm{NH}_{4}^{+}$and $\mathrm{CI}$ did not show any chemical difference between the farms. However, other chemical species had significant differences. The manure heap was highly efficient in the removal of $\mathrm{NO}_{2}$. and $\mathrm{NO}_{3}^{-}$ions and had low efficiency for $\mathrm{NH}_{4}^{+}$ions. Concentration of ions $\mathrm{Cl}^{-}, \mathrm{NH}_{4}^{+}$ and $\mathrm{Ca}^{+2}$ increased during the animals ${ }^{\prime}$ finishing period, whereas the other chemical species decreased or maintained concentrations.

KEY WORDS: Agriculture and cattle-breeding wastes; Swine-breeding; Treatment.

\section{INTRODUÇÃO}

Nos últimos anos a suinocultura tem crescido e se consolidado na forma de integração dos produtores com as agroindústrias, adotando principalmente o sistema de animais confinados (CHEN 2009). A água utilizada no manejo e na higienização das instalações associadas às fezes e urina dos animais é dita dejeto líquido de suíno (DLS) (SOUZA et al., 2009). O volume e a composição dos DLS variam em função do animal, da fase e do manejo, dentre outros aspectos (AMARO et al., 2006; GONÇALVES JUNIOR, 2008; SOUZA et al., 2009). Os maiores volumes gerados de DLS são compreendidos na fase de terminação dos animais, que consiste em fazer o animal ganhar peso até o momento do abate. Durante este período, o peso dos animais varia de 25 a $100 \mathrm{~kg}$, e produzem, em média, 07 litros de dejeto 
por dia (KONZEN et al., 1997; KUNZ et al., 2005a). O DLS é rico em macronutrientes (N, P, K), micronutrientes ( $\mathrm{Zn}, \mathrm{Cu}, \mathrm{Mn}$ ), carbono orgânico e inorgânico (GATIBONI et al., 2008; GIROTTO et al., 2010; VEIGA et al., 2012).

Tendo em vista as propriedades químicas oriundas do DLS, ele é considerado uma importante fonte de adubo orgânico usado pelos agricultores na fertilização das lavouras, podendo substituir, parcial ou totalmente, o fósforo exigido pelas plantas (SANTOS; CAMARGO, 2008). Além disso, se usado adequadamente pode substituir também os fertilizantes químicos, melhorando as características químicas, físicas e microbiológicas do solo, fornecendo nutrientes para a produção agrícola (MEDEIROS et al., 2007; KONZEN; ALVARENGA 2007; ASSMANN et al., 2009). No âmbito social, a inclusão dos resíduos orgânicos, como o DLS na adubação, tem fortes implicações sobre a promoção do manejo racional de nutrientes, ampliando o ciclo de vida de reservas minerais, bem como na redução de riscos ambientais (SAMPAIO, 2013). No entanto, um dos fatores negativos da utilização do DLS é em relação ao uso inadequado e contínuo, que culmina com a contaminação de águas superficiais e subterrâneas, pois pelo excesso, os dejetos ficam biodisponíveis e são transportados pelo escoamento superficial ou lixiviados (KLEINMAN et al., 2009). Ainda assim, o uso excessivo do DLS pode causar contaminação do solo pelo acúmulo de espécies químicas (COUTO et al., 2010; SCHERER et al., 2010), sendo que, dentre os nutrientes, o $\mathrm{Cu}$ e o $\mathrm{Zn}$ tem sido os principais elementos encontrados na camada superficial do solo, pois sua absorção é insuficiente comparado ao número de aplicações de dejeto (PERALA et al., 2006; MKHABELA et al., 2009). A contaminação pelo uso acentuado de DLS causa alterações nas características químicas, físicas e biológicas do solo, além da poluição atmosférica (PIEPER, 2006; ASSMANN et al., 2007).

Vários autores vêm estudando tecnologias para o tratamento do DLS, tais como as lagoas de decantação, lagoas facultativas, lagoas de armazenamento, de maturação, biodigestores e vários tipos de filtros (KUNZ et al., 2005b; ARAÚJO 2012; RIZZONI et al., 2012; SANTOS et al., 2014). No Brasil a recomendação técnica para o manejo destes resíduos é o uso de reatores anaeróbicos, no qual se busca reduzir a carga orgânica, o teor de nutrientes e de organismos patogênicos (KONZEN, 2006). O DLS, depois de produzido, é conduzido por tubulações para o sistema 
de armazenamento, geralmente para as esterqueiras anaeróbicas, e posteriormente é armazenado em lagoas por um período estabelecido pela legislação, para que sofra fermentação anaeróbia (SCHERER et al., 1996; AITA et al., 2007). A legislação estadual de Santa Catarina estabelece o período de 120 dias de armazenamento dos dejetos nas esterqueiras (FATMA, 2000). Após este período os dejetos podem ser destinados às lavouras agrícolas como fertilizante orgânico, sendo esta a sua principal utilização (MENEZES et al., 2007; DAL BOSCO et al., 2008; SCHREINER; SAMPAIO, 2008). Esta alternativa pode ser considerada uma alternativa racional quando empregadas às práticas agrícolas adequadas, no entanto, como dito, pode ser também uma preocupação ambiental pelo uso irracional como, por exemplo, o uso sem os critérios técnicos de recomendação de adubação ou de uso repetitivo em uma mesma área (HIGASHIKAWA et al., 2010; HENTZ; CARVALHO, 2014). É de extrema importância conhecer as características do solo e da cultura onde será aplicado o DLS, isso é dado pelo fato de as culturas apresentarem diferentes exigências em nutrientes, e pelos solos possuírem características distintas em relação à capacidade de troca catiônica e do teor de matéria orgânica (KUNZ, 2009).

Apesar das legislações, como a do Estado de Santa Catarina, que estabelece o limite máximo de $50 \mathrm{~m}^{3}$. ha. ano-1 (FATMA, 2000), ou as recomendações do Estado do Rio Grande do Sul, onde o DLS aplicado no solo não deve ultrapassar os limites de nutrientes exigidos pelas culturas, muitos agricultores têm extrapolado os volumes aplicados em uma mesma área (CQFS-RS/SC, 2004). Desta forma, os órgãos ambientais passaram a considerar a suinocultura como a atividade com o maior potencial de contaminação do solo e da água (CERETTA et al., 2003). Esta contaminação varia com o volume aplicado, com as condições climáticas e, principalmente, em função das características químicas e físicas do dejeto e do solo. Vários estudos já foram realizados em relação ao DLS, principalmente abordando de maneira geral, a viabilidade de uso como fertilizante orgânico, contaminações e acúmulo de elementos no solo. Em um dos estudos, Berwange et al. (2008) avaliaram as alterações na concentração do fósforo (P) ocorridas em amostras de solo coletadas em áreas com frequentes aplicações de DLS, visando estimar o potencial de risco de contaminação ambiental. Ceretta et al. (2005) avaliaram a eficiência do uso do DLS na nutrição de plantas, visando obter informações para o uso mais eficiente 
destes dejetos, e evitando potencializar sua capacidade poluidora. Aita et al. (2007) analisaram a taxa de nitrificação do nitrogênio amoniacal $\left(\mathrm{NH}_{3}-\mathrm{N}\right)$ dos dejetos líquidos de suínos, em sistema de plantio direto aplicado ao solo. Silva et al. (2014) classificaram a influência da aplicação de diferentes doses de DLS na comunidade da fauna do solo em diferentes sistemas de manejo do solo. Em outro estudo Souza et al. (2014) estudaram a eficiência do sistema de lagoas de estabilização em uma granja de suínos, na redução do potencial poluidor, por meio de análises físicoquímicas dos dejetos coletados em diferentes fases do sistema.

O manejo do dejeto líquido de suínos, bem como sua forma de tratamento, tem sido intensamente estudado. No entanto, evoluções e magnitudes das concentrações durante as diferentes fases de criação em relação à forma de tratamento dos dejetos não são abordadas com frequência nos estudos realizados. Neste intuito o presente estudo teve por objetivo a avaliação das concentrações de alguns nutrientes no dejeto líquido de suíno originado da fase de terminação, antes a após o tratamento em esterqueira, em três granjas produtoras de suínos no município de Piratuba, Santa Catarina, Brasil.

\section{MATERIAL E MÉTODOS}

O estudo compreendeu a coleta e análise de amostras de DLS, em diferentes intervalos de tempo, na fase de terminação dos suínos. O estudo foi realizado em três granjas produtoras de suínos, localizadas no município de Piratuba - SC, região meio Oeste de Santa Catarina (Figura 1). As características das granjas estão apresentadas na Tabela 1 .

As granjas possuem três esterqueiras de diferentes capacidades de armazenamento de dejetos. Em todas elas o processo de tratamento dos dejetos ocorre na forma de batelada, onde todos os dejetos são destinados primeiro a uma esterqueira e, a partir desta os dejetos são destinados para outra e assim sucessivamente, de modo a, atender o tempo de retenção estabelecido pela legislação. 


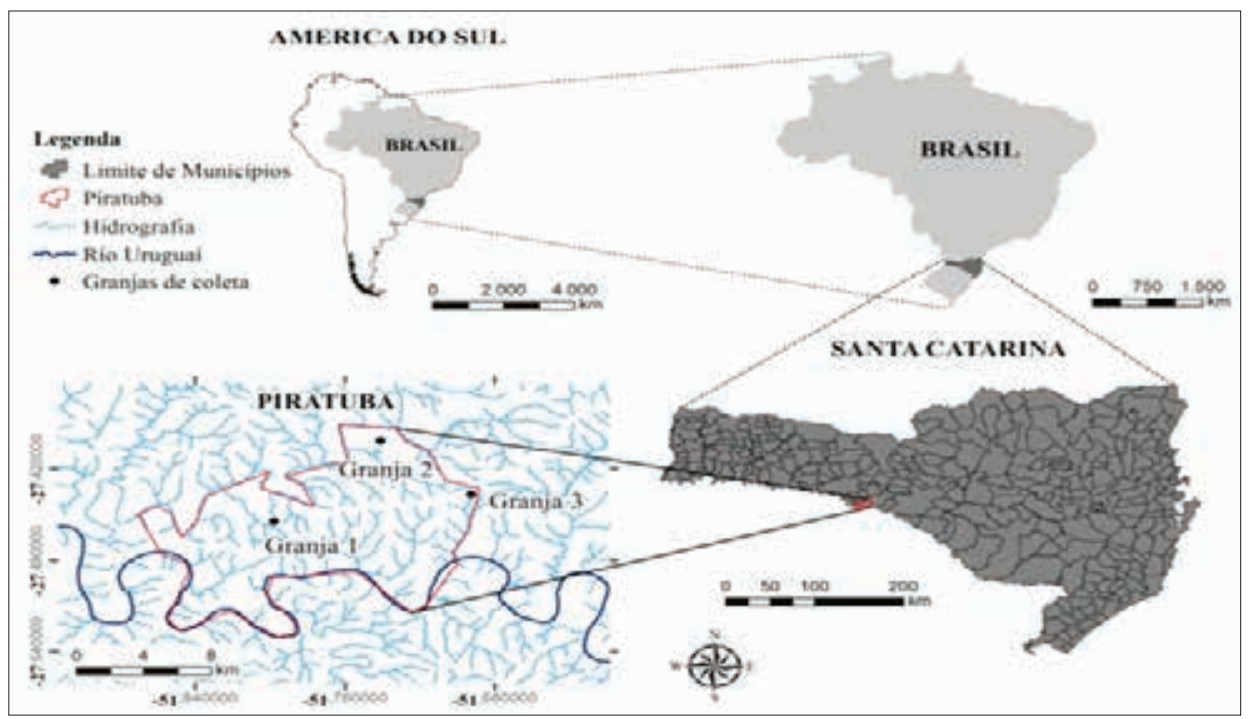

Figura 1. Mapa da localização do município de Piratuba - SC e das três granjas avaliadas. Fonte: os autores (2015).

A amostragem dos dejetos foi realizada na entrada do sistema de tratamento (calhas coletoras de dejeto), sendo representativa ao dejeto líquido suíno bruto e, na saída do sistema de tratamento (última esterqueira) representando o resíduo teoricamente "tratado". As coletas na entrada das esterqueiras foram realizadas ao longo da fase de terminação dos suínos, em intervalos de 30 dias, a partir do momento em que os animais foram alojados até a saída para o abate. O período de alojamento dos suínos nas diferentes granjas variou de 120 a 125 dias. As amostragens na saída do dejeto foram realizadas 120 dias após o início do armazenamento, correspondendo o tempo de detenção estabelecido pela legislação.

Tabela 1. Caracterização das granjas avaliadas, do município de Piratuba - SC

(Continua)

\begin{tabular}{lccc}
\hline \multicolumn{1}{c}{ Granja } & $\mathbf{1}$ & $\mathbf{2}$ & $\mathbf{3}$ \\
\hline Local & Linha Planalto & Linha Hachamam & Lageado Mariano \\
Latitude & $27^{\circ} 27^{\prime} 14^{\prime}$ & $27^{\circ} 24^{\prime} 30^{\prime}$ & $27^{\circ} 26^{\prime} 54^{\prime}$ \\
Longitude & $51^{\circ} 47^{\prime} 49^{\prime}$ & $51^{\circ} 44^{\prime} 29^{\prime}$ & $51^{\circ} 41^{\prime} 32^{\prime}$ \\
\hline
\end{tabular}


(Conclusão)

\begin{tabular}{lccc}
\hline \multicolumn{1}{c}{ Granja } & $\mathbf{1}$ & $\mathbf{2}$ & $\mathbf{3}$ \\
\hline Sistema de criação & Terminação & Terminação & Terminação \\
Número de animais & 1010 & 1480 & 420 \\
Empresa integradora & $\mathrm{X}$ & $\mathrm{X}$ & $\mathrm{Y}$ \\
Número de rações & 9 & 9 & 5 \\
Tecnificação & alta & alta & média \\
Número de esterqueiras & 3 & 3 & 3 \\
$\begin{array}{l}\text { Capacidade total } \\
\text { de armazenamento }\left(\mathbf{m}^{3}\right)\end{array}$ & 1000 & 1500 & 500 \\
Tempo retenção $($ dias $)$ & 120 & 120 & 120 \\
\hline
\end{tabular}

*120 dias: tempo estabelecido pela IN $\mathrm{N}^{\circ} 11$ / FATMA/SC, para armazenamento dos dejetos (2000).

A comparação das concentrações na entrada e na saída do sistema de tratamento permitiu a avaliação da eficiência de remoção das espécies químicas, sendo determinada pela seguinte expressão:

$$
E f=\frac{C e-C s}{C e} 100
$$

em que, Ef é a eficiência de remoção da espécie química considerada (\%), Ce é a concentração média na entrada do sistema de tratamento $\left(\mathrm{ng} \mathrm{L}^{-1}\right)$ e $C s$ é a concentração média na saída do sistema de tratamento ( $\left.\mathrm{mg} \mathrm{L}^{-1}\right)$.

Em cada uma das granjas foram realizadas cinco coletas de dejetos, sendo que em cada coleta, foram realizadas três amostragens em diferentes pontos da calha, fazendo assim a triplicata das amostras. As amostras coletadas foram acondicionadas em frascos de polietileno com capacidade de $50 \mathrm{~mL}$ e mantidas a uma temperatura média de $4^{\circ} \mathrm{C}$, em caixa de isopor com gelo e, em seguida, enviadas ao laboratório para procedimento analítico.

Para a determinação das concentrações das espécies químicas: cloreto $(\mathrm{Cl})$, nitrito $\left(\mathrm{NO}_{2}^{-}\right)$, nitrato $\left(\mathrm{NO}_{3}^{-}\right)$, fosfato $\left(\mathrm{PO}_{4}^{-3}\right)$, sulfato $\left(\mathrm{SO}_{4}^{-2}\right)$, sódio $\left(\mathrm{Na}^{+}\right)$, amônia $\left(\mathrm{NH}_{4}^{+}\right)$, 
potássio $\left(\mathrm{K}^{+}\right)$, magnésio $\left(\mathrm{Mg}^{2+}\right)$ e cálcio $\left(\mathrm{Ca}^{2+}\right)$ utilizou-se um cromatógrafo de troca iônica, marca $D I O N E X{ }^{\circledR}$, modelo ICS-90. Este equipamento é constituído de duas colunas de separação, uma aniônica e outra catiônica juntamente com supressora e um detector de condutividade. As condições de injeção da amostra, temperatura, vazão de gás foram: coluna aniônica: injeção da amostra: $10 \mathrm{~mL}$; temperatura: $30^{\circ} \mathrm{C}$; taxa de fluxo: $1,2 \mathrm{~mL}$ min..$^{-1}$; eluente: $\mathrm{Na}_{2} \mathrm{CO}_{3} 4,5 \mathrm{mM} / \mathrm{NaHCO}_{3} 1,4 \mathrm{mM}$; condutividade esperada: $19-23 \mu \mathrm{S}$ supressor: aniônico autorregenerante; solução estoque: $\mathrm{NaHCO}_{3} 100 \mathrm{mM}$; corrente aplicada: $31 \mathrm{~mA}$. Para a coluna catiônica: $25 \mathrm{~mL}$; temperatura: $30^{\circ} \mathrm{C}$; taxa de fluxo: $0,5 \mathrm{~mL} \mathrm{min.}{ }^{-1}$; eluente: $20 \mathrm{mM} \mathrm{H}_{2} \mathrm{SO}_{4}$; condutividade: $<2 \mu \mathrm{S}$ supressor: catiônico autorregenerante; solução regenerante estoque: TBAOH (Tetrabutyl Ammonium) 2,06 M; corrente aplicada: $30 \mathrm{~mA}$. As curvas de calibração foram realizadas com padrões obtidos junto à DIONEX®, utilizando-se cinco pontos na faixa de 0,4 a $250 \mathrm{mg} \mathrm{L}^{-1}$ com leitura em quintuplicata. Para maior precisão nos resultados as leituras das concentrações foram realizadas em triplicatas. Na Figura 2 é apresentado o cromatograma do padrão aniônico e do catiônico obtidos no cromatógrafo.

A determinação das concentrações de carbono total (CT) dividido em carbono orgânico total (COT) e carbono inorgânico (CI), das amostras foram analisados diretamente no analisador de carbono orgânico total marca SHIMADZU®, modelo $T O C-V C P H$. As curvas de calibração foram realizadas com padrões obtidos junto à $Q H E M I S \circledR$, utilizando-se cinco pontos na faixa de 1 a $100 \mathrm{mg} \mathrm{L}^{-1}$ com leitura em quintuplicata. As leituras das concentrações foram realizadas em triplicatas.
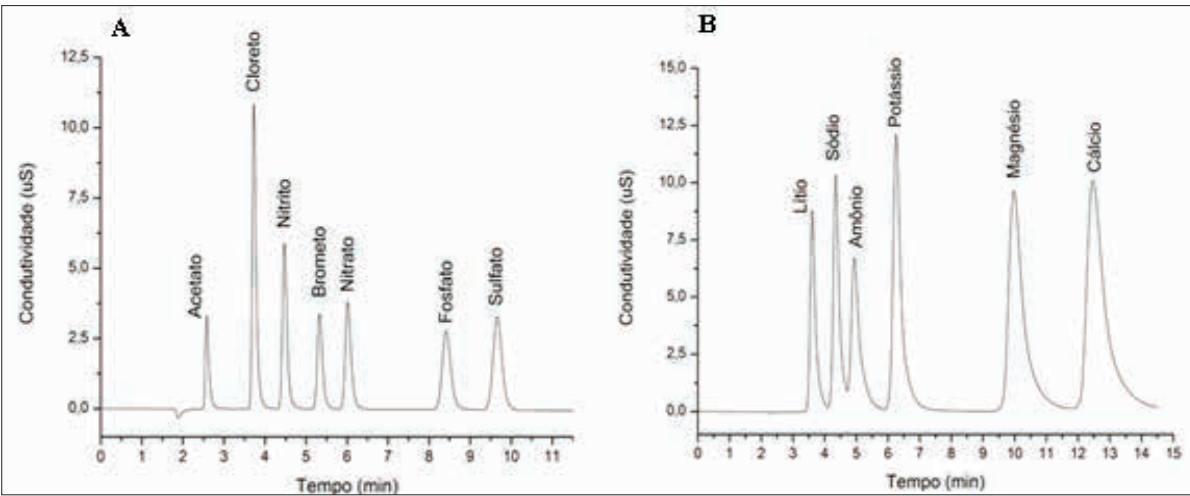

Figura 2. Cromatogramas do padrão ânions (A) e cátions (B) obtidos no cromatógrafo. 
Os dados foram tratados com análises estatísticas correntes, médias e comparações com a análise de variância. A análise de variância (Analysis of Variance, ANOVA) foi aplicada para comparar as concentrações das granjas, visando avaliar semelhanças estatísticas. As comparações neste estudo foram feitas em nível de significância de $5 \%(\alpha=0,05)$ para todas as espécies químicas. A Anova foi executada no software PAST, versão 2.14 (HAMMER et al., 2001).

\section{RESULTADOS E DISCUSSÃO}

Os resultados das características químicas dos dejetos coletados nas três granjas da fase de terminação são apresentados na Tabela 2. Nas análises estatísticas, foi considerado que as granjas 1 e 2 possuem sistema de manejo similar. Os íons cloreto, amônio, nitrato, fosfato e cálcio e carbono inorgânico apresentaram diferenças significativas nas suas concentrações para ambas as granjas. Desta forma, entende-se que os fatores manejo, números de animais e capacidade de armazenamento das esterqueiras, podem ter contribuído para diferença das concentrações. Quanto aos íons de sódio e nitrito, não foi encontrada diferença significativa. Os íons nitrato, fosfato e cálcio também apresentaram diferença significativa entre os tratamentos. Estes resultados podem ser explicados de acordo com Amaral et al. (2006), em que descrevem que os constituintes do DLS estão relacionados com a proporção de fezes e urina, sexo, composição da ração, volume de água ingerida e utilizada na higienização das baias, que influenciam sobre íons nitrato, fosfato e cálcio. Outro fator que pode influenciar os resultados das concentrações observadas nas granjas 1 e 2 em relação à granja 3 é o volume da água utilizada, que proporciona a diluição das espécies químicas na massa líquida. Vale citar que, de que acordo com Oliveira (2000), o DLS apresenta em seu conteúdo apenas 10\% de matéria seca.

O resultado estatístico para os íons potássio, magnésio, sulfato e carbono orgânico possibilitou avaliar que o manejo, número de animais e técnicas mais sofisticadas de manejo não resultaram em diferenças significativas. As diferenças estão relacionadas à redução de aproximadamente 6,15 e 16 vezes para os íons potássio, magnésio, sulfato e aumento de duas vezes o carbono orgânico, quando comparado aos resultados de Sediyama et al. (2009) em um estudo que se analisou DLS com fermentação anaeróbica em caixas de fibra de vidro, maturado durante 30 dias. Segundo Souza et al. (2014), a disparidade entre as concentrações pode estar 
relacionada com as diferentes formulações de rações fornecidas aos suínos.

Tabela 2. Concentrações médias dos elementos determinados no DLS não tratado

\begin{tabular}{cccc}
\hline Elementos & Granja 1 & Granja 2 & Granja 3 \\
\hline Cloreto $(\mathbf{C l})$ & $798,15^{\mathrm{a}}$ & $1.224,50^{\mathrm{b}}$ & $1.016,84^{\mathrm{c}}$ \\
Amônio $\left(\mathbf{N H}_{4}^{+}\right)$ & $1.483,3^{\mathrm{a}}$ & $1.804,64^{\mathrm{b}}$ & $1.062,56^{\mathrm{c}}$ \\
Nitrito $\left(\mathbf{N O}_{2}{ }^{-}\right)$ & $6,2^{\mathrm{a}}$ & $5,18^{\mathrm{a}}$ & $4,37^{\mathrm{a}}$ \\
Nitrato $\left(\mathbf{N O}_{3}{ }^{-}\right)$ & $14,35^{\mathrm{a}}$ & $17,9^{\mathrm{a}}$ & $24,03^{\mathrm{b}}$ \\
Fosfato $\left(\mathbf{P O}_{3}^{-3}\right)$ & $85,9^{\mathrm{a}}$ & $81,9^{\mathrm{a}}$ & $46,66^{\mathrm{b}}$ \\
Sulfato $\left(\mathbf{S O}_{3}^{-2}\right)$ & $216,8^{\mathrm{a}}$ & $312,3^{\mathrm{b}}$ & $233,48^{\mathrm{a}}$ \\
Sódio $\left(\mathbf{N a}^{+}\right)$ & $3.394,2^{\mathrm{a}}$ & $3.707,7^{\mathrm{a}}$ & $4.203,75^{\mathrm{a}}$ \\
Potássio $\left(\mathbf{K}^{+}\right)$ & $1.473,1^{\mathrm{a}}$ & $1.942,0^{\mathrm{b}}$ & $1.979,91^{\mathrm{a}}$ \\
Magnésio $\left(\mathbf{M g}^{2+}\right)$ & $903,0^{\mathrm{a}}$ & $432,9^{\mathrm{b}}$ & $449,96^{\mathrm{b}}$ \\
Cálcio $\left(\mathbf{C a}{ }^{2+}\right)$ & $2.069,4^{\mathrm{a}}$ & $2.125,9^{\mathrm{a}}$ & $1.498,90^{\mathrm{b}}$ \\
TOC & $4.063,3^{\mathrm{a}}$ & $3.144,9^{\mathrm{b}}$ & $4.622,35^{\mathrm{a}}$ \\
$\mathbf{I C}$ & $352,2^{\mathrm{a}}$ & $590,2^{\mathrm{b}}$ & $758,52^{\mathrm{c}}$ \\
\hline
\end{tabular}

Valores seguidos por letras diferentes na mesma linha diferem entre si, em nível de significância de $5 \%$.

O carbono orgânico total e sódio apresentaram as concentrações mais altas dentre as análises, chegando a 4.622,35 $\mathrm{mg} \mathrm{L}^{-1} \mathrm{e} 4.203,75 \mathrm{mg} \mathrm{L}^{-1}$, respectivamente. Além deste, o íon amônio também apresentou elevadas concentrações, variando entre 1.062,56 $\mathrm{mg} \mathrm{L}^{-1}$ a 1.804,64 $\mathrm{mg} \mathrm{L}^{-1}$. O íon amônio é uma molécula instável, o qual através da elevação do $\mathrm{pH}$ pode ser convertida em amônia e, na sequência do processo de nitrificação, em nitrito e em nitrato. As altas concentrações de amônio são confirmadas por Fioreze et al. (2012), que verificaram que o DLS possui elevadas concentrações de nitrogênio na forma amoniacal. As concentrações do íon potássio encontradas nas análises foram relativamente altas, alcançando a concentração máxima de $1.979,91 \mathrm{mg} \mathrm{L}^{-1}$. A presença de altas concentrações de potássio no DLS pode ser atribuída a sua forma mineral ser altamente solúvel em água (CERETTA et al., 2003).

Os íons sódio, cálcio, potássio e fósforo também apresentaram altas 
concentrações. Nesta análise é importante destacar a relação das altas concentrações de carbono orgânico total e das baixas concentrações dos demais nutrientes, pois segundo CQFS RS/SC (2004), grande parte dos nutrientes contidos nos dejetos está na forma orgânica, transformando-se em formas minerais ou disponíveis para as plantas. Além disso, o aumento do conteúdo de massa seca dos dejetos promove maior concentração de nutrientes (HONEYMAN, 2005).

Na Figura 3 são apresentados os resultados da eficiência na remoção dos cátions e ânions e de carbono nas esterqueiras. O tratamento anaeróbio realizado nas esterqueiras mostrou maior eficiência para os íons fosfato e nitrito, apresentando $21,01 \%$ e $67,09 \%$, respectivamente. Em um estudo que busca avaliar as condições físico-químicas do dejeto suíno armazenado, Santos et al. (2007) determinaram menores concentrações de ortofosfato ao final dos 120 dias de armazenamento, e conclui que a esterqueira proporciona condições favoráveis à migração deste elemento da fase líquida para a fase sólida.

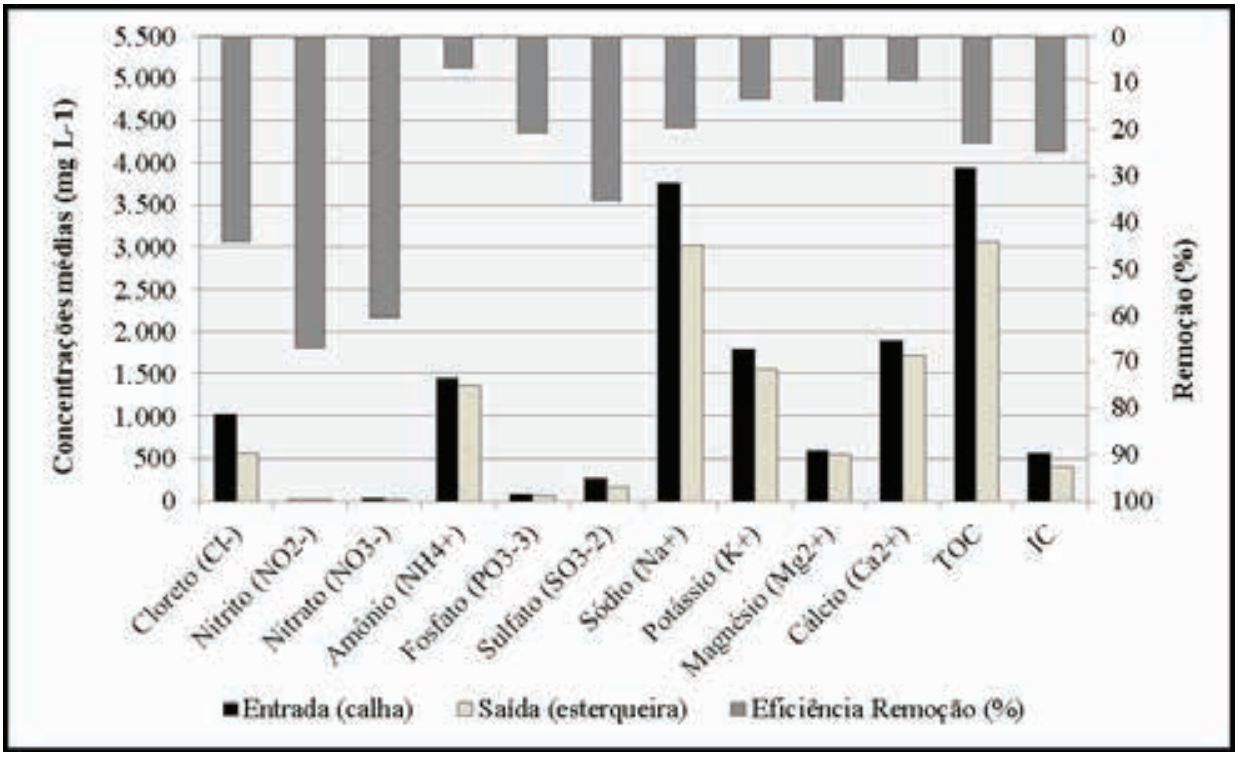

Figura 3. Concentrações médias e porcentagem de elementos removidos do DLS pela tratamento da esterqueira após 120 dias de maturação.

Os íons nitrito e nitrato foram os nutrientes que apresentaram as maiores 
porcentagens de remoção, 67,09 e 60,39\%, respectivamente. Os resultados encontrados neste estudo se encontram bem próximos ao de Santos et al. (2007), que verificaram remoção de 51,72\% de N-NO 2 em período de maturação de 120 dias. A alta remoção do nitrito e nitrato está relacionada à volatilização do nitrogênio. Em seus estudos com tratamento de dejeto suíno por diferentes sistemas, Vivan et al. (2010) confirmaram que a volatilização é a principal via de remoção de nitrogênio. Mas mesmo assim Ball-Coelho et al. (2006) ressaltaram que sucessivas aplicações de dejeto em uma mesma área aumentam os níveis de nitrogênio no solo.

Os íons cloreto e sódio apresentaram a maior concentração na entrada dos dejetos (calha) 1.013,17 e 3.768,59 $\mathrm{mg} \mathrm{L}^{-1}$, tendo uma redução na saída (esterqueira) para 567,35 e 3.019,78 $\mathrm{mg} \mathrm{L}^{-1}$, correspondendo a 44,13 e 19,66\%, respectivamente. $\mathrm{O}$ íon amônio foi o que apresentou a menor porcentagem de remoção, correspondendo a 6,96\%. As altas concentrações do íon amônio são preponderantes às afirmações de Payet et al. (2009), que afirmaram que 60\% do nitrogênio encontrado no DLS estão na forma de íons amônio, sendo que, após aplicado no solo, o nitrogênio sofre o processo de nitrificação transformando-se em nitrato, que é a forma que as plantas irão absorver.

Os íons potássio, magnésio e cálcio apresentaram valores relativamente baixos de remoção 13,42, 13,63 e 9,45\%, respectivamente, quando comparados aos resultados reportados por Souza et al. (2014), que relataram uma remoção de 66,7; 40,0 e 31,0\% respectivamente. De acordo com a legislação ambiental que classifica os corpos d'água, o íon potássio não é caracterizado como poluente em corpos hídricos classe 1 ou especial (SILVA et al., 2003). O íon fosfato apresentou uma concentração de $71,53 \mathrm{mg} \mathrm{L}^{-1}$ resultado esse que foi semelhante à de Souza et al. (2014), que determinaram $84,8 \mathrm{mg} \mathrm{L}^{-1}$ de fósforo total. A remoção deste íon na esterqueira foi de $21,01 \%$ ou $15,58 \mathrm{mg} \mathrm{L}^{-1}$. Esta remoção foi a menor encontrada por Santos et al. (2007), que relataram reduções de fosfato que chegaram a 44,72\%. Mas foi superior à encontrada por Godos et al. (2009), que obteve remoção de 10\% do fósforo em estudos em lagoa de tratamento com altas taxas de microalgas. A baixa remoção culmina as altas concentrações que ocorrem nos dejetos e promove a contaminação dos corpos das águas. Segundo Prior et al. (2009), o fósforo é um dos elementos com maior potencial para comprometer a qualidade das águas. 
O carbono apresentou disparidade entre a parte do carbono orgânico total (COT) e do carbono inorgânico (CI), sendo que o COT apresentou concentração muito superior ao CI. No entanto, a fração solúvel de carbono colabora com a atividade microbiana e heterotrófica do solo e com as bactérias redutoras do nitrato (GONZATTO et al., 2013). Todavia, o carbono orgânico dissolvido está na formula ideal para a absorção das plantas, porém fica vulnerável a lixiviação para águas subterrâneas.

A Tabela 3 corresponde à evolução das concentrações médias durante o período que compreendeu o estudo, ou seja, durante o período em que os animais permaneceram nas baias durante os 120 dias de alojamento. Os íons cloreto, amônio e cálcio aumentaram suas concentrações ao longo período, de 963,70; 1.400,12 e $1.898,62 \mathrm{mg} \mathrm{L}^{-1}$ para $1.022,35 ; 1.523,27$ e $1.945,61 \mathrm{mg} \mathrm{L}^{-1}$, ou seja, o cloreto teve aumento de $6,08 \%$, o âmnio de $8,82 \%$ e o cálcio de $2,47 \%$. O íon cloreto atua no metabolismo da água e fotossíntese das plantas, no entanto, seu excesso provoca a necrose das folhas (CARVALHO et al., 2005). Entretanto, o íon fosfato teve menos interação com o tratamento proposto, e sua concentração variou de $76,53 \mathrm{mg} \mathrm{L}^{-1}$ para $68,80 \mathrm{mg} \mathrm{L}^{-1}$, concentração essa que representa 449,3 vezes superior a estabalecida pela legislação vigente (BRASIL, 2005).

Tabela 3. Evolução das concentrações médias dos elementos avaliados durante o período de coleta dos dejetos

(Continua)

\begin{tabular}{ccccc}
\hline & \multicolumn{5}{c}{ Dias } \\
\cline { 2 - 5 } Elementos & 30 & 60 & 90 & 120 \\
\hline Cloreto $(\mathbf{C l})$ & 963,70 & $1.026,82$ & $1.039,79$ & $1.022,35$ \\
Nitrito $\left(\mathbf{N O}_{2}^{-}\right)$ & 5,41 & 6,35 & 4,38 & 5,21 \\
Nitrato $\left(\mathbf{N O}_{3}^{-}\right)$ & 20,20 & 19,14 & 16,93 & 15,56 \\
Fosfato $\left(\mathbf{P O}_{3}^{-3}\right)$ & 67,53 & 76,46 & 66,85 & 68,80 \\
Sulfato $\left(\mathrm{SO}_{3}^{-2}\right)$ & 266,01 & 255,21 & 250,31 & 228,72 \\
Sódio $\left(\mathbf{N a}^{+}\right)$ & $3.606,58$ & $3.881,26$ & $3.862,50$ & $3.363,73$ \\
Amônio $\left(\mathbf{N H}_{4}^{+}\right)$ & $1.400,12$ & $1.413,96$ & $1.423,93$ & $1.523,27$ \\
Potássio $\left(\mathbf{K}^{+}\right)$ & $1.748,21$ & $1.750,03$ & $1.828,83$ & $1.649,59$ \\
\hline
\end{tabular}


Evolução e magnitude das concentrações de cátions, ânions e carbono no dejeto líquido de...

\begin{tabular}{ccccc}
\hline \multirow{2}{*}{ Elementos } & \multicolumn{4}{c}{ Dias } \\
\cline { 2 - 5 } & $\mathbf{3 0}$ & $\mathbf{6 0}$ & $\mathbf{9 0}$ & $\mathbf{1 2 0}$ \\
\hline Magnésio $\left(\mathbf{M g}^{2+}\right)$ & 581,11 & 645,22 & 569,26 & 549,96 \\
Cálcio $\left(\mathrm{Ca}^{2+}\right)$ & $1.898,62$ & $2.022,48$ & $1.822,94$ & $1.945,61$ \\
TOC & $4.085,29$ & $3.992,88$ & $3.835,68$ & $3.530,64$ \\
IC & 566,37 & 578,65 & 584,92 & 526,92 \\
\hline
\end{tabular}

Os íons nitrito, nitrato, sulfato, sódio, potássio e magnésio apresentaram redução em suas concentrações no período do estudo, demostrando que o tratamento proposto é eficiente para a remoção ou redução das especies químicas analisadas. No entanto, Zordan et al. (2008) descreveram que os tratamentos mais adequados para DLS são o emprego de lagoa anaeróbia e lagoa facultativa. Dentre as vantagens com tratamentos com lagoas de estabilização, pode-se descrever alto desempenho na remoção de matéria orgânica e sólidos, com baixo custo de implantação e manutenção (SOUZA et al., 2014). Entretanto, o íon nitrato apresentou resultado semelhantes ao encontrado por Santos et al. (2007), que estudando dejetos suínos, encontraram concentração de $\mathrm{N}^{-\mathrm{NO}_{3}}$ - de $15,95 \mathrm{mg} \mathrm{L}^{-1}$ nos primeiros 30 dias, sendo reduzidas para 14,83 $\mathrm{mg} \mathrm{L}^{-1} 120$ dias. De acordo com Oviedo-Rondón (2008), o nitrato é altamente solúvel em águas, e quando aplicado por meio de dejeto líquido suíno pode atingir facilmente o lençol freático.

\section{CONCLUSÃO}

As maiores concentrações de espécies químicas determinadas no DLS foram o COT, $\mathrm{Na}^{+}, \mathrm{Ca}^{2+}, \mathrm{K}^{+}$e $\mathrm{NH}_{4}^{+}$.

Os íons $\mathrm{Cl} ; \mathrm{NH}_{4}^{+}$e IC apresentaram diferença significativa nas suas concentrações para todas as granjas, podendo ter sido influenciada pela capacidade de armazenamento das esterqueiras projetadas e pela sua diluição. Já para os íons $\mathrm{K}^{+}, \mathrm{Mg}^{2+}, \mathrm{SO}_{4}^{-2}$ e COT, foi possível concluir que o manejo e o número de animais não influenciaram em suas concentrações.

O tratamento anaeróbio realizado pela fermentação do DLS nas esterqueiras foi eficiente na remoção dos íons $\mathrm{NO}_{2}$ e $\mathrm{NO}_{3}$, atingindo valores acima de $60 \%$ 
de remoção. Entretanto para os compostos de carbono não houve diferenças significativas, mesmo o COT apresentando concentração 7,5 vezes superior ao CI.

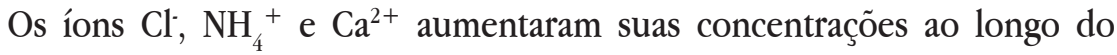
tempo, enquanto $\mathrm{NO}_{2} ; \mathrm{NO}_{3} ; \mathrm{SO}_{3}^{-2}, \mathrm{Na}^{+}, \mathrm{K}^{+}$e $\mathrm{Mg}^{2+}$ reduziram suas concentrações. Esta disciparidade entre perdas e acúmulo de nutrientes estão fortemente ligados aos processos de volatização e mineralização dos compostos. Parece evidente que o tempo de detenção hidráulica do DLS estabelecido pela legislação é fundamental para a redução das espécies químicas.

\section{REFERÊNCIAS}

AITA, C.; GIACOMINI, S. J.; HÜBNER, A. P. Nitrificação do nitrogênio amoniacal de dejetos líquidos de suínos em solo sob sistema de plantio direto. Pesquisa Agropecuária Brasileira, Brasília, v. 42, n. 1, p. 95-102, 2007.

AMARAL, A. L.; SILVEIRA, P. R. S.; LIMA, G. J. M. M.; KLEIN, C. S.; PAIVA, D. P.; MARTIINS, F.; KICH, J. D.; ZANELLA, J. R. C.; FÁVERO, J.; LUDKE, J. V.; BORDIN, L. C.; MIELE, M.; HIGARASHI, M. M.; MORÉS, N.; COSTA, O. A. D.; OLIVEIRA, P. A. V.; BERTOL, T. M.; SILVA, V. S. Boas práticas de produção de suínos. Concórdia: EMBRAPA, 2006. (Circular Técnica -50).

AMARO, S.; RIBEIRO, L.; PARALTA, E.; CARDOSO PINTO, F. Aplicação de efluentes de suinoculturas como fertilizantes na agricultura: impacto na qualidade dos meios hídricos (Santiago do Cacém, Alentejo). In: CONGRESSO DA ÁGUA, 8., 2006, Santiago do Cacém, Alentejo. Anais... Santiago do Cacém, Alentejo: Associação Portuguesa dos Recursos Hídricos, 2006, p. 9.

ARAÚJO, I. S.; OLIVEIRA, J. L. R.; ALVES, R. G. C.; BELLI FILHO, P.; COSTA, R. H. R. Avaliação de sistema de tratamento de dejetos suínos instalado no Estado de Santa Catarina. Revista Brasileira de Engenharia Agrícola e Ambiental, Campina Grande, v. 16, n. 7, p. 745-753, 2012.

ASSMANN, J. M.; BRAIDALL, J. A.; CASSOL, L. C.; MAGIEROL, E. C.; MANTELI, C.; RIZ, E. Produção de matéria seca de forragem e acúmulo de nutrientes em pastagem 
anual de inverno tratada com esterco líquido de suíno. Ciência Rural, Santa Maria, n. 39, p. 2408-2416, 2009.

ASSMANN, T. S.; ASSMANN, J. M.; CASSOL, L. C.; DIEHL, R. C.; MANTELI, C.; MAGIERO, E. C. Desempenho da mistura forrageira de aveia-preta mais azevém e atributos químicos do solo em função da aplicação de esterco líquido de suínos. Revista Brasileira de Ciência do Solo, Viçosa, v. 31, n. 6, p. 1515-1523, 2007.

BALL-COELHO, B. R.; ROY, R. C.; BRUIN, A. J. Nitrogen recovery and partitioning with different rates and methods of side dressed manure. Soil Science Society of America Journal, v. 70, n. 2, p. 464-73, 2006.

BERWANGER, A. L.; CERETTA, C. A.; SANTOS, D. R. Alterações no teor de fósforo no solo com aplicação de dejetos líquidos de suínos. Revista Brasileira de Ciência do Solo, Viçosa, v. 32, p. 2525-2532, 2008.

BRASIL. CONAMA - Conselho Nacional do Meio Ambiente. Resolução N 357/2005. Dispõe sobre a classificação dos corpos de água e diretrizes ambientais para o seu enquadramento, bem como estabelece as condições e padrões de lançamento de efluentes, e da outras providências, p. 58-63, 2005.

CARVALHO, J. C. R. SOUSA, C. S. Manual: Fertilizantes e fertilização. Escola de Agronomia - UFBA. 2005. 159p.

CERETTA, C. A.; BASSO, C. J.; PAVINATO, P. S.; TRENTIN, E. E.; GIROTTO, E. Produtividade de grãos de milho, produção de matéria seca e acúmulo de nitrogênio, fósforo e potássio na rotação aveia preta/milho/nabo forrageiro com aplicação de dejeto líquido de suínos. Ciência Rural, Santa Maria, v. 35, n. 6, 2005.

CERETTA, C. A.; DURIGON, R.; BASSO, C. J.; BARCELOS, L. A. R.; VIEIRA, F. C. B. Características químicas de solo sob aplicação de esterco líquido de suínos em pastagem natural. Pesquisa Agropecuária Brasileira, Brasília, v. 38, n. 6, p. 729$735,2003$.

CHEN, D. W. Nutrition and feed strategies for sustainables wine production in China. 
Frontiers of Agriculture in China, v. 4, n. 3, p. 471-477, 2009.

COUTO, R. R.; COMIN, J. R.; BEBER, C. L.; URIARTE, J. F.; BRUNETTO, G.; BELLI FILHO, P. Atributos químicos em solos de propriedades suinícolas submetidos a aplicações sucessivas de dejeto de suínos no município de Braço do Norte, Santa Catarina. Scientia Agrária, Curitiba, v. 11, n. 6, p. 493-497, 2010.

CQFS-RS/SC - COMISSÃO DE QUÍMICA E FERTILIDADE DO SOLO. Manual de adubação e calagem para os estados do Rio Grande do Sul e Santa Catarina. Porto Alegre: SBCS/NRS/URFRGS, 2004. 400 p.

DAL BOSCO, T. C.; IOST, C.; SILVA, L. N.; CARNELLOSI, C. F.; EBERT, D. C.; SCHREINER, J.; SAMPAIO, S. C. Utilização de água residuária de suinocultura em propriedade agrícola - estudo de caso. Irriga, Botucatu, v. 13, n. 1, p. 139-144, 2008.

FATMA - FUNDAÇÃO DO MEIO AMBIENTE (2000). Instrução Normativa Estadual No 11. Disponível em: http:<//www.fatma.sc.gov.br>. Acesso em: 03 de fev. 2015.

FIOREZE, C.; CERETTA, C. A.; GIACOMINI, S. J.; TRENTIN, G.; LORENSINI, F. Liberação do $\mathrm{N}$ em solos de diferentes texturas com ou sem adubos orgânicos. Ciência Rural, Santa Maria, v. 42, n. 7, p. 1187-1192, 2012.

GATIBONI, L. C.; BRUNETTO, G.; KAMINSKI, J; RHEINHEIMER, D. S.; CERETTA, C. A.; BASSO, C. J. Formas de fósforo no solo após sucessivas adições de dejeto líquido de suínos em pastagem natural. Revista Brasileira de Ciência do Solo, Viçosa, v. 32, n. 4, p. 1753-761, 2008.

GIROTTO, E.; CERETTA, C. A.; BRUNETTO, G.; SANTOS, D. R.; SILVA, L. S.; LOURENZI, C. R.; LORENSINI, F.; RENAN VIEIRA, C. B.; SCHMATZ, R. Acúmulo e formas de cobre e zinco no solo após aplicações sucessivas de dejeto líquido de suínos. Revista Brasileira de Ciência do Solo, Viçosa, v. 34, n. 3, 2010.

GODOS, I.; VARGAS, V. A.; BLANCO, S.; GONZÁLEZ, M. C. G.; SOTO, R.; GARCÍAENCINA, P. A.; BECARES, E.; MUÑOZ, R. A comparative evaluation of microalga e for the degradation of pig gery wastewater under photosyn the ticoxygenation. 
Bioresource Technology, v. 101, p. 5150-5158, 2010.

GONÇALVES JUNIOR, A. C.; LINDINO, C. A.; ROSA, M. F.; BARICCATTI, R.; GOMES, G. D. Remoção de metais pesados tóxicos cádmio, chumbo e cromo em biofertilizante suíno utilizando macrófita aquática (Eichorniacrassipes) como bioindicador. Acta Scientiarum Technology, Maringá, v. 30, n. 1, p. 9-14, 2008.

GONZATTO, I. R.; MIOLA, E. C. C.; DONEDA, A.; PUJOL, S. B.; AITA, C.; GIACOMINI, S. J. Volatilização de amônia e emissão de óxido nitroso após aplicação de dejetos líquidos de suínos em solo cultivado com milho. Ciência Rural, Santa Maria, v. 43, n. $9,2013$.

HAMMER, O.; HARPER, D. A. T.; RYAN, P. D. PAST: Paleontological statistics software package for education and data analysis. Palaeontologia Electronica, v. 4, 2001. Disponível em: < http://nhm2.uio.no/norlex/past/download.html>. Acesso em: 02 abril 2015.

HENTZ, P.; CARVALHO, N. L. Impactos ambientais da fertilização orgânica em sistemas agropecuários na região sul-brasileira. Revista Eletrônica em Gestão, Educação e Tecnologia Ambiental, Santa Maria, v. 18, n. 1, p. 340-352, 2014.

HIGASHIKAWA, F. S.; SILVA, C. A.; BETTIOL, W. Chemica and physical properties of organic residues. Revista Brasileira de Ciência do Solo, Viçosa, v. 34, p. 1743$1752,2010$.

HONEYMAN, M. S.; HARMON, J. D. Performance of finishing pigs in hoop structures and confinement during winter and summer. Journal of Animal Science, Champaign, v. 81, n. 5, p. 1663-1670, 2003.

KLEINMAN, P. J. A. E.; SHARPLEY, A. N.; SAPORIT, L. S.; BRYANT, R. Aplication of manure to no-till soils: phosphorus losses by sub-surface an surface pathways. Nutrients Cycling Agroecosystems, n. 84, p. 215-227, 2009.

KONZEN, E. A. Viabilidade ambiental e econômica de dejetos de suínos. Sete Lagoas: Embrapa Milho e Sorgo, 2006. 27p. (Série Documentos, 59). 
KONZEN, E. A.; ALVARENGA, R. C. Cultura do milho. Fertilidade de solos. Adubação orgânica. In: SEMINÁRIO TÉCNICO DA CULTURA DE MILHO, 5, 2007, Videira. Anais... Videira: Empresa Brasileira de Pesquisa Agropecuária - Embrapa, 2007.

KONZEN, E. A.; PEREIRA FILHO, I. A.; BAHIA FILHO, A. F. C.; PEREIRA, F. A. Manejo do esterco líquido de suínos e sua utilização na adubação do milho. Sete Lagoa: EMBRAPA- CNPMS, 1997. 31p. (EMBRAPA-CNPMS. Circular Técnica, 25).

KUNZ, A. Transformações da Produção Animal no Brasil e suas Consequências Ambientais. In: I SIMPÓSIO INTERNACIONAL SOBRE GERENCIAMENTO DE RESÍDUOS DE ANIMAIS, 2009, Florianópolis, SC. Anais... Concórdia: 2009.

KUNZ, A.; CHICHETTA, O.; MIELLE, M.; GIROTTTO, A. F.; SANGOI, V. Comparativo de custos de implantação de diferentes tecnologias de armazenamento/ transporte e distribuição de dejetos de suínos. Concórdia: Embrapa. 2005a. (Circular Técnico, n. 42).

KUNZ, A.; HIGARASHI, M. M.; OLIVEIRA, P. A. Tecnologia de manejo e tratamento de dejetos de suínos estudadas no Brasil. Cadernos de Ciências \& Tecnologia, Brasília, v. 22, n. 3, p. 651-665, 2005b.

MEDEIROS, L. T.; REZENDE, A. V.; VIEIRA, P. F.; NETO, F. R. C.; VALERIANO, A. R. Produção e qualidade da forragem de Capim-Marandu fertiirrigado com dejetos líquidos de suínos. Revista Brasileira de Zootecnia, Viçosa, v. 36, n. 2, p. 309-318, 2007.

MENEZES, J. F. S.; KONZER, E. A.; SILVA, G. P.; SANTOS, S. C. G.; PIMENTA, F. F.; LOPES, J. P. C.; ALVARENGA, R. C.; ANDRADE, C. L. T. Aproveitamento de dejetos de suínos na produção agrícola e monitoramento do impacto ambiental. Universidade de Rio Verde - GO, p. 46, 2007. (Boletim Técnico 6).

MKHABELA, M. S.; GORDON, R.; BURTON, D.; SMITH, E.; MADANI, A. The impact of management practices and meteorological conditions on ammonia and nitrous oxide emissions following application of hog slurry to forage grass in Nova Scotia. 
Agriculture, Ecosystems and Environment, Amsterdam, v. 130, p. 41-49, 2009.

OLIVEIRA, P. A. V. Produção de suínos em sistemas deep bedding: experiência brasileira. In: SEMINÁRIO INTERNACIONAL DE SUINOCULTURA, 5. 2000, São Paulo. Anais... Concórdia: EMBRAPA, Suínos e Aves, 2000. p. 89-100.

OVIEDO-RONDON, E. O. Tecnologias para mitigar o impacto ambiental da produção de frangos de corte. Revista Brasileira de Zootecnia, Viçosa, v. 37, p. 239-252, 2008.

PAYET, N.; FINDELING, A.; CHOPART, J. L.; FEDER, F.; NICOLINI, E. A.; SAINT MACARY, H.; VAUCLIN, M. Modelling the fate of nitrogen following pig slurry application on a tropical croppedacid soil on the island of Réunion (France). Agriculture Ecosystems and Environment, v. 134, n. 3-4, p. 218-233, 2009.

PERALA, P.; KAPUINEN, P.; ESALA, M.; TYNELA, S.; REGINA, K. Influence of slurry and mineral fertilizer application techniques on $\mathrm{N}_{2} \mathrm{O}$ and $\mathrm{CH}_{4}$ fluxes from a barley field in southern Finland. Agriculture, Ecosystems and Environment, Amsterdam, v. 17, p. $71-78,2006$.

PIEPER, N. A. Controle da contaminação ambiental decorrente da suinocultura no Rio Grande do Sul: manual técnico. Recursos Hídricos. Porto Alegre: SEMA, 2006.

RIOR, M.; SMANHOTTO, A.; SAMPAIO, S. C.; NOBREGA, L. H.; OPAZO, M. A. U.; DIETER, J. Acúmulo e percolação de $\mathrm{P}$ no solo devido à aplicação de água residuária de suinocultura na cultura do milho (Zea mays L.). Pesquisa Aplicada e Agrotecnologia, v. 2, n. 1, p. 89-96, 2009.

RIZZONI, L.B.; TOBIAS, A. C. T.; DEL BIANCHI, M.; GARCIA, J. A. D. Biodigestão anaeróbia no tratamento de dejetos de suínos. Revista Cientifica Eletrônica de Medicina Veterinária, Garça, n. 8, 2012.

SAMPAIO, A. O. Afinal, queremos ou não viabilizar o uso agrícola do lodo produzido em estação de esgoto sanitário? Uma avaliação crítica da Resolução CONAMA N 375 , 
Revista DAE, São Paulo, n. 193, p. 16-27, 2013.

SANTOS, G. A.; CAMARGO, F. A. O. Fundamentos da matéria orgânica no solo: ecossistemas tropicais e subtropicais. 2. ed. Porto Alegre: Metrópole, 2008.

SANTOS, L. D.; MAYERLE, S. F.; CAMPOS, L. M. S. Tecnologias e sistemas de tratamento para os dejetos da suinocultura. Revista Verde de Agroecologia e Desenvolvimento Sustentável, Pombal, v. 9, n. 12, 2014.

SANTOS, M. A. A.; SCMIDT, V.; BITENCOURT, V. C.; MAROSO, M. T. D. Esterqueiras: avaliação físico-química e microbiológica do dejeto suíno armazenado. Engenharia Agrícola, Jaboticabal, v. 27, n. 2, p. 537-543, 2007.

SCHERER, E. E.; AITA, C.; BALDISSERA, I. T. Avaliação da qualidade do esterco líquido de suínos da Região Oeste Catarinense. EPAGRI; Concórdia - SC. 12p. 1996.

SCHERER, E. E.; NESI, C. N.; MASSOTTII, Z. Atributos químicos do solo influenciados por sucessivas aplicações de dejetos suínos em áreas agrícolas da Região Oeste Catarinense. Revista Brasileira Ciência do Solo, Viçosa, v. 34, p. 1375-1383, 2010.

SCHREINER, J. S.; SAMPAIO, S. C. Utilização de água residuária de suinocultura em propriedade agrícola - estudo de caso. Irriga, Botucatu, v. 13, p. 139-144, 2008.

SEDIYAMA, M. A. N.; SANTOS, M. R; VIDIGAL, S. M.; SALGADO, L. T.; PEDROSA, M. W.; JACOB, L. L. Produtividade e estado nutricional do quiabeiro em função da densidade populacional e do biofertilizante suíno. Bragantia, Campinas, v. 68, n. 4, p. 913-920, 2009.

SILVA, F. F.; FREITAS, P. S. L.; BERTONHA, A.; REZENDE, R.; GONÇALVES, A. C. A.; DALLACORT, R. Flutuações das características químicas do efluente industrial de fecularia de mandioca. Acta Scientiarum Agronomy, Maringá, v. 25, n. 1, p. 167$175,2003$.

SILVA, R. F.; BERTOLLO, G. M.; CORASSA, G. M.; COCCO, L. B.; STEFFEN, R. B.; 
BASSO, C. Doses de dejeto líquido de suínos na comunidade da fauna edáfica em sistema plantio direto e cultivo mínimo. Ciência Rural, Santa Maria, v. 44, n. 3, 2014.

SOUZA, A. T.; CAMPOS, A. T.; SILVA, E. B.; GANDINI, A. M. M.; CORRÊA, J. M. Redução do potencial poluidor de dejetos de suínos em lagoas de estabilização em série. Bioscience Journal, Uberlândia, v. 30, n. 1, p. 65-73, 2014.

SOUZA, C. S.; CAMPOS, J.; MATOS, A.; FERREIRA, W. Caracterização de dejetos de suínos em fase de terminação. Revista Ceres, Viçosa, v. 56, 2009.

VEIGA, M.; PANDOLFO, C. M.; JUNIOR, A. A. B.; SPAGNOLLO, E. Chemical attributes of a Hapludox soil after nine years of pig slurry application. Pesquisa Agropecuária Brasileira, Brasília, v. 47, n. 12, p. 1766-1773, 2012.

VIVAN, M.; KUNZ, A.; STOLBERG, J.; PERDOMO, C.; TECHIO, V. H.Eficiência da interação biodigestor e lagoas de estabilização na remoção de poluentes em dejetos de suínos. Revista Brasileira de Engenharia Agrícola e Ambiental, Campina Grande, v. 14, p. 320- 325, 2010.

ZORDAN, M. S.; SALÉH, B. B.; MENDONÇA, A. Eficiência na remoção de nutrientes em lagoas de estabilização da granja escola FESURV. Global Science and Technology, v. 1, n. 1, p. 51-62, 2008.

Recebido em: 26 de maio de 2015 Aceito em: 25 de setembro de 2016 
